\title{
Software company bans competitive users
}

Jim Giles, London

Chemists who have been banned from using a leading software package because they use competing products have taken their fight online.

The group has set up an anonymous website to draw attention to the behaviour of Gaussian of Wallingford, Connecticut.

The site, which appeared about three months ago, provides a list of scientists who are "banned by Gaussian", and says it aims to "shed light on some practices of Gaussian, Inc. that can undermine basic scientific ideals".

Gaussian's software is used by theoretical chemists around the world to predict molecular properties such as bond length and reaction energy. Thousands of site licences for Gaussian have been sold at about US\$2,000 each for academic use.

But a small number of prominent researchers have been banned from using the software. Since the early 1990s, Gaussian has denied licences to chemists who work on software that replicates parts of Gaussian's functionality.

Researchers who are issued with licences must also agree not to allow access to banned chemists. At least ten scientists have been denied licences.

"It's like a worker from Ford not being able to buy a Chrysler car," says Peter Gill, a banned chemist from the University of Nottingham, UK.
The banned researchers say that the company's actions go beyond normal competitive practices. They argue that the restrictions prevent them from acting as referees on other papers, and from properly checking $\mathrm{PhD}$ theses, as they are unable to use the software to replicate their colleagues' results.

"I have only reviewed about half of the 40 to 50 papers I normally review in a year," says Mark Gordon, a theoretical chemist at Iowa

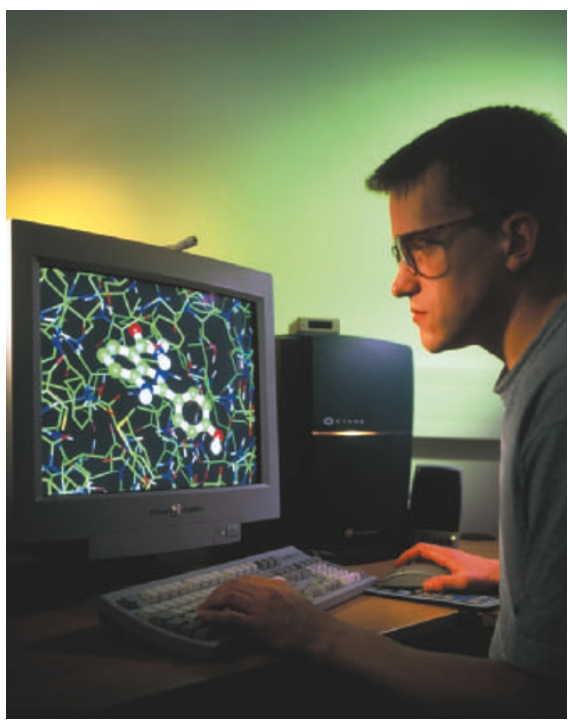

Log off: Gaussian fears that rivals could use its programs to "catch up with less effort".
State University. Gordon found out he was banned when he tried to buy Gaussian software about 18 months ago. He works on a theoretical-chemistry package known as GAMESS, which is distributed for free.

Gaussian's president, Michael Frisch, says that providing licences to competitors would allow rivals to learn about Gaussian's features without having to develop those features themselves. "Having a competitor's program allows them to catch up with less effort," he says. He also says that some researchers with competing products have previously published inaccurate comparisons of the speed of their programs compared with Gaussian.

Frisch acknowledges that it is good practice to check calculations during peer review, but denies that it is essential.

"Provided that the method is written up and published I don't normally redo calculations," agrees Mike Robb, a theoretical chemist at Imperial College London, who has worked on the development of Gaussian.

Gaussian says it has no plans to change its policy. Some researchers point out that the problems faced by banned researchers could be reduced if the many individual programs that replicate parts of Gaussian were integrated into a single product.

Researchers funded by the US Department of Energy are working on a software package that combines some of these programs. They declined to be interviewed.

\section{Charging plan casts a shadow on Japan's light beam}

\section{David Cyranoski, Tokyo}

At the moment, it's free - but academic researchers may soon have to pay to use one of the world's most powerful synchrotrons.

Under a plan being considered by the Japanese science ministry, academics would have to join their industrial colleagues in paying to use SPring-8 in Hyogo.

The proposal has already led SPring-8 researchers to begin a worldwide appeal to combat the user fee, which they will say will undermine research priorities at the facility.

SPring- 8 has 48 beamlines of intense, stable light that are used by physicists, chemists and biologists to study the structure of molecules and crystalline materials. Like most such facilities, it charges some industrial scientists for beam use. But last month the science ministry ordered the facility to conduct a feasibility study on charging all of its users.

"SPring-8 was expensive to build and has high maintenance costs," says Yasunori Kojima, director of the ministry's office of synchrotron radiation research. "These are tough times, and we have to think about how to make scientists bear some of the burden."

It is not clear how much the user fee would be. But Akito Kakizaki, a physicist at the University of Tokyo's Institute for Solid State Physics, is heading a group of 13 researchers who say that any amount would change research priorities for the worse. The group, which is a subcommittee of the Japan Society of Nuclear and Radiochemical Sciences, has written to international synchrotron facilities for support.

The user fees would have to come from grants, which in turn would be beefed up to account for the extra costs. But according to Murray Gibson, director of the Advanced Photon Source in Argonne, Illinois, this system leaves funding in the hands of people too distant from the synchrotron facility to make good decisions.

Gibson has written to Kakizaki saying that he is "seriously concerned" about the "counter-productive" user-fee proposal. Michael Chesters, who heads the Daresbury Synchrotron Radiation Source in Warrington, UK, also supports Kakizaki. His facility charged scientists for beam time until two years ago, when the pay scheme was cancelled. The charges made some worthwhile projects look disproportionately costly, says Chesters, leading to inappropriate decisions about who could use the beam. "Once the country has decided it is important to build the facility, it shouldn't punish those who want to use it most extensively," he says.

Kakizaki's group will send its report to SPring-8 officials by the end of this month. A second group, headed by Hiromichi Kamitsubo, a former director of SPring-8, is also working on a report that will evaluate the proposal and the changes in funding needed to make the system work. The science ministry will make its decision about user fees by the end of this year. www.spring8.or.jp/e 